\title{
Sensorless Control of a Fault Tolerant Multi-level Inverter PMSM Drives in Case of an Open Circuit Fault
}

\author{
Kamel Saleh \\ Electrical Engineering Dept \\ An-Najah National University, Nablus, West Bank \\ Kamel.saleh@najah.edu
}

\begin{abstract}
This paper introduces a fault tolerant multi-level inverter PMSM Drive that is capable to work in case of a single phase open circuit fault without degrading the system performance. Moreover, it can work in sensorless mode in case of an open circuit fault with the same performance as in sensor mode. The permanent magnet synchronous motor (PMSM) is fed by a 4leg asymmetric cascaded $\mathrm{H}$-Bridges multi-level inverter. The fourth leg is activated in case of an open circuit only to maintain the system performance. The reliability of the system is additionally enhanced by adopting a new method to track saliency position in case of an open circuit fault to make the system work in sensorless mode. The saliency position is obtained through measuring the dynamic current response of the healthy motor line currents due to the insulated-gate bipolar transistor (IGBT) switching actions. The new strategy includes software modifications only to the saliency tracking algorithm used in healthy mode in order to make it applicable to the reconfigured multi-level inverter in the presence of a fault. It uses only the fundamental pulse width modulation (PWM) waveform (i.e. there is no modification to the operation of the 4-leg multi-level inverter), similar to the fundamental PWM method proposed for a 3-leg multi-level inverter. Simulation results are provided to verify the effectiveness of the proposed strategy over a wide range of speeds in the case of a single-phase open circuit fault.
\end{abstract}

Keywords-Four-leg multi-leve; sensorless; single-phase open circuit; space vector pulse width modulation.

\section{INTRODUCTION}

Sensorless control of motor drives using 2-level converters has been widely researched for systems employing standard two-level converters [1-6]. These techniques introduce a significant additional current distortion which causes audible noise, torque pulsations and increases the system losses. In the other hand, a Multi-level converter can achieve a higher voltage and power capability with conventional switching devices compared to 2-level converter and is now used for high power drives $[7,8,9]$. The particular structure of some of these converters offers significant potential for improving sensorless control of motors, as they employ $\mathrm{H}$-bridge circuits with a relatively low DC link voltage. [10-12] are introducing different techniques to achieve sensorless control of multi-level inverter drives in healthy mode i.e no open circuit fault. Under faulty conditions, a number of fault-tolerant strategies to control 2level motor drives [13-18] and multi-level motor drives[19-22] have been used to enhance system operation under open circuit phase faults in sensor mode. [23,24] introduced a 4-leg 2-level (PMSM) drive to track the saturation saliency in the case of single-phase open circuit faults. This paper is introducing a new method to track the saturation saliency in a surface mounted permanent magnet motor in case of an open circuit fault. This motor is driven by a 4-leg multi-level inverter. The

\author{
Mark Sumner \\ School of electrical engineering \\ Nottingham University, Nottingham,UK \\ Mark.sumner@nottingham.ac.uk
}

objective is to maintain continuous system operation with a satisfactory performance to meet the safety procedure for the whole system and increase the reliability of the system.

\section{RESEARCH METHOD}

\section{A. Fault tolerant multi-level four-leg converter drive topology}

Fig 1 shows the proposed fault tolerant multi-level 4-leg converter drive topology. In this topology, a fourth leg is added to the conventional 3-leg multi-level inverter. The redundant leg is permanently connected the motor neutral point to provide the fault-tolerant capability in case of an open phase fault. Under healthy operating conditions, the fourth leg will be redundant which means that the two switches in this leg will be inactivated resulting in no connection between the supply and the motor neutral point. Therefore, the proposed converter normally operates as a conventional multi-level three-leg inverter as shown in fig 2. Under faulted operating conditions, the switches on the faulty phase are disabled and the switches in the fourth leg are immediately activated in order to control the voltage at the neutral point of the motor.

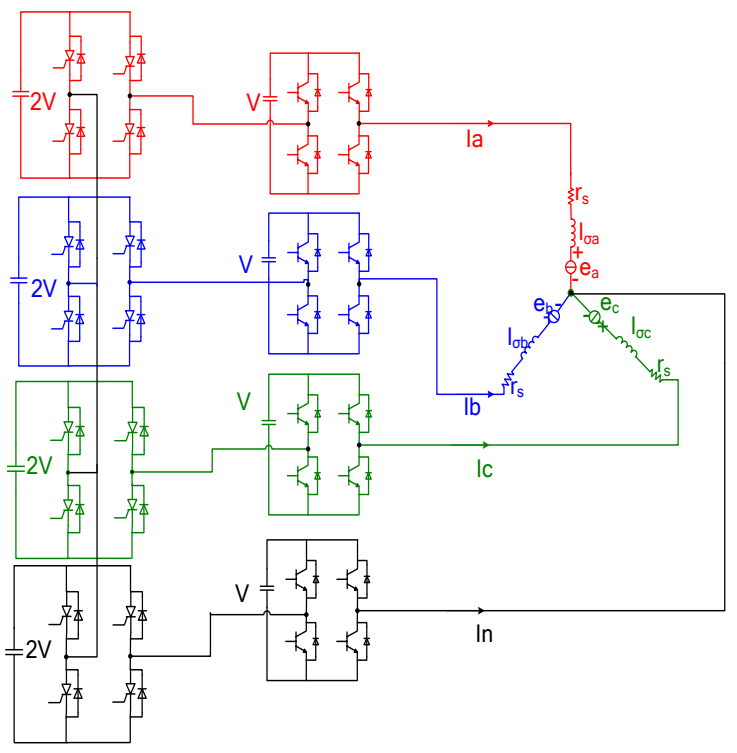

Fig 1 4-leg asymmetric cascaded H-Bridge seven level converter.

\section{B. Healthy operation of the multi-level inverter}

The control strategy of the system in sensored healthy mode is illustrated in Figure 2. The reference voltages that are calculated from the controllers are used to generate pulses to control the multi-level inverter through Space Vector Pules Width Modulation Technique (SVPWM).

The multi-level SVPWM technique that is adopted in this paper is given in [8]. According to this technique the switching 
sequence will be one of four types as illustrated in Fig 3 (type 0), Fig 4 (type 1), Fig 5(type 2) and Fig 6 ( type 3.

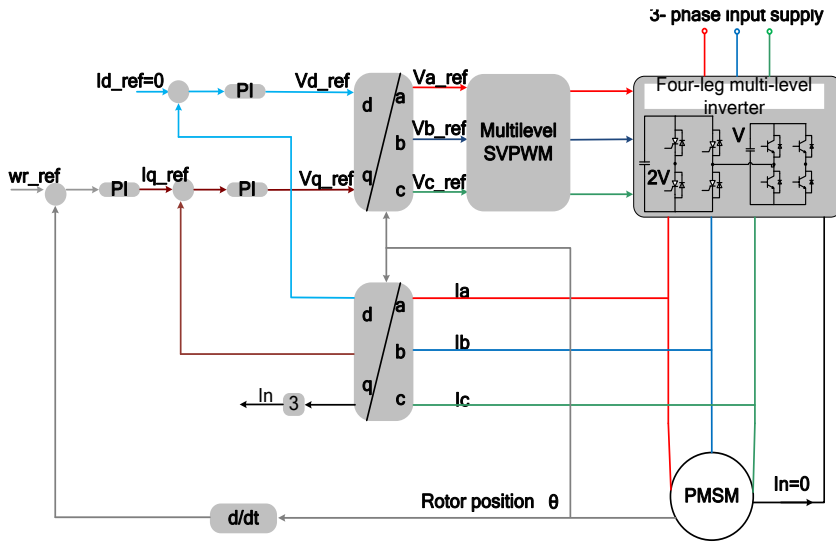

Fig 2 The vector control structure for the four-phase multi-level inverter PMSM drive under in healthy mode.
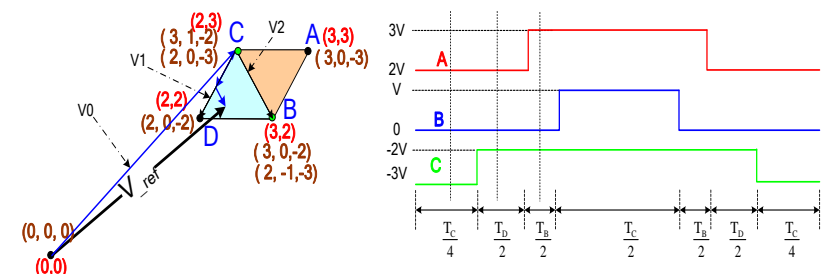

Fig 3 Switching sequence and timing diagram of type 0 used in SVPWM for the multilevel converter.
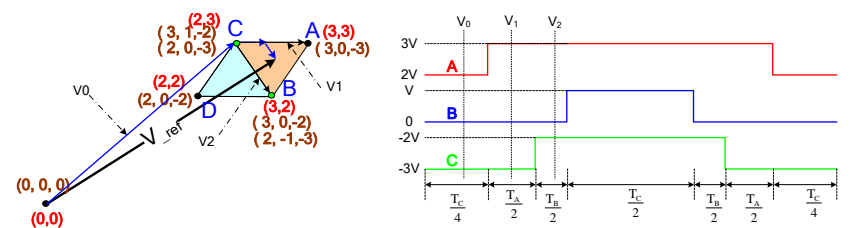

Fig 4 Switching sequence and timing diagram of type 1 used in SVPWM for the multilevel converter.

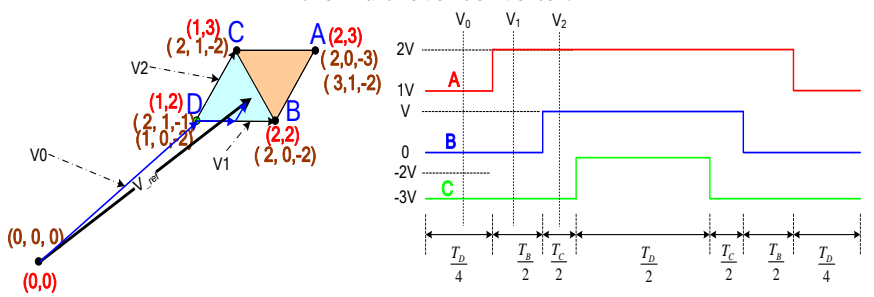

Fig 5 Switching sequence and timing diagram of type 2 used in SVPWM for the multilevel converter

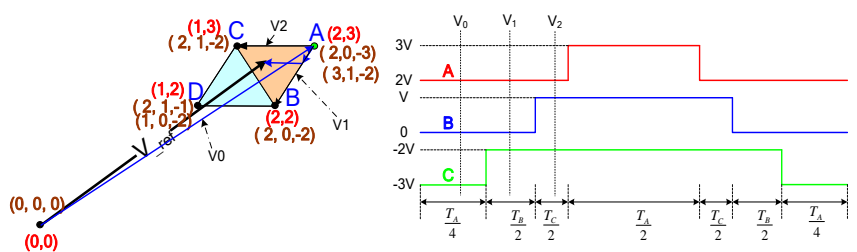

Fig 6 Switching sequence and timing diagram of type 3 used in SVPWM for the multilevel converter

\section{Open phase fault operation}

The modification introduced to the control strategy of the system under open phase fault condition is illustrated in Figure 7 in the case that an open circuit occurs in phase be as an example [18,23]. Firstly, in order to disable the switches in the phase $b$, the reference voltage of the faulty phase Vb_ref is set to zero whereas the motor neutral current, which is the sum of the two remaining output currents can circulate through the fourth phase of the multi-level inverter. Secondly, as the current in the faulty phase becomes zero $(\mathrm{Ib}=0)$, and in order to maintain the motor performance under faulty operation, the rotating magnetomotive force obtained from the armature currents (Ia, $\mathrm{Ib}, \mathrm{Ib}$ ) in the healthy condition should be maintained by the two remaining motor currents (Ia and Ic) in the case of an open circuit fault that demands an increase of $a \sqrt{3}$ as well as phase shifting 30 degrees away from the faulted phase compared to the currents generated under normal operation, as given in Eq. (1). If the fault is occurred in other phase, the same algorithm will be applied.

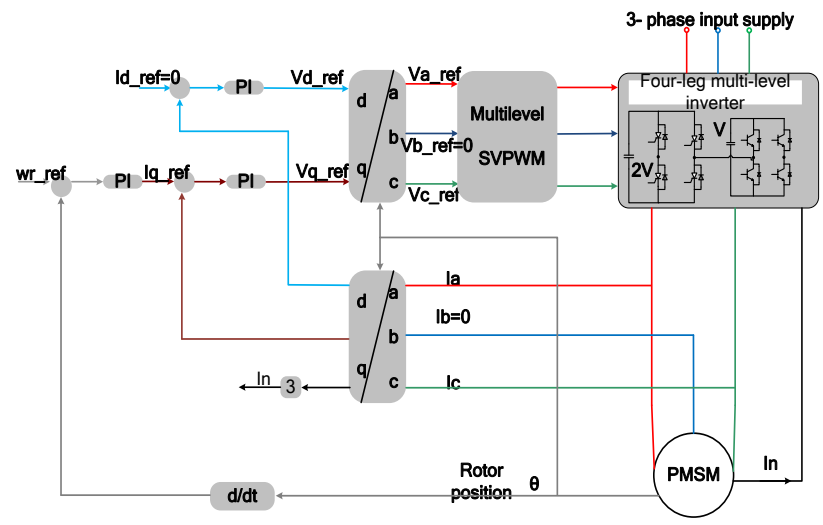

Figure7. The vector control structure for the four-phase multi-level inverter PMSM drive under a phase ' $b$ ' open-circuit fault.

$$
\left[\begin{array}{l}
i a \\
I 0 \\
I c
\end{array}\right]=\left[\begin{array}{cc}
\sqrt{3} \cos (\theta+30) & \sqrt{3} \sin (\theta+30) \\
-\cos (\theta-120) & -\sin (\theta-120) \\
\sqrt{3} \cos (\theta+90) & \sqrt{3} \sin (\theta+90)
\end{array}\right]\left[\begin{array}{l}
V q \\
V d
\end{array}\right]
$$

The simulation of a 4-leg multi-level converter PMSM drive was carried out using SABER. Figure 8 shows the simulation results of a 4-leg multi-level inverter PMSM drive system under healthy and faulted conditions. The motor was driving a $30 \mathrm{Nm}$ load torque at $300 \mathrm{rpm}$ speed. Then speed step commands from $300 \mathrm{rpm}$ to $1100 \mathrm{rpm}$ back to $300 \mathrm{rpm}$ were applied at times $2 \mathrm{~s}, 3 \mathrm{~s}, 4 \mathrm{~s}, 6 \mathrm{~s}, 7 \mathrm{~s}$, and $8 \mathrm{~s}$ to the motor. In time intervals between $2.5 \mathrm{~s}$ to $3.5 \mathrm{~s}$ an open circuit phase fault was introduced to phase ' $a$ ' while an open circuit in phase ' $b$ ' was introduced in time interval between $4.5 \mathrm{~s}$ to $5.5 \mathrm{~s}$. Finally, in time interval between $6.5 \mathrm{~s}$ and $7.5 \mathrm{~s}$ the open circuit fault was introduced to phase ' $\mathrm{c}$ '.. It is clear that the controller could regulate the motor speed to follow the reference speed properly under faulted conditions as well as under normal operation. The controlled currents id and iq were stable at the reference level. Under faulted conditions, the amplitude of the motor currents was multiplied by $\sqrt{3}$ and the two remaining healthy currents became phase shifted by $60^{\circ}$ while the neutral currents was no longer zero as given in eq (1). For the rest of the test, i.e under healthy condition, The motor currents are balanced 3-phase sinusoidal and the neutral current is zero.. The simulation results show that ripple in the torque is almost the same as that exist under normal operating conditions. 


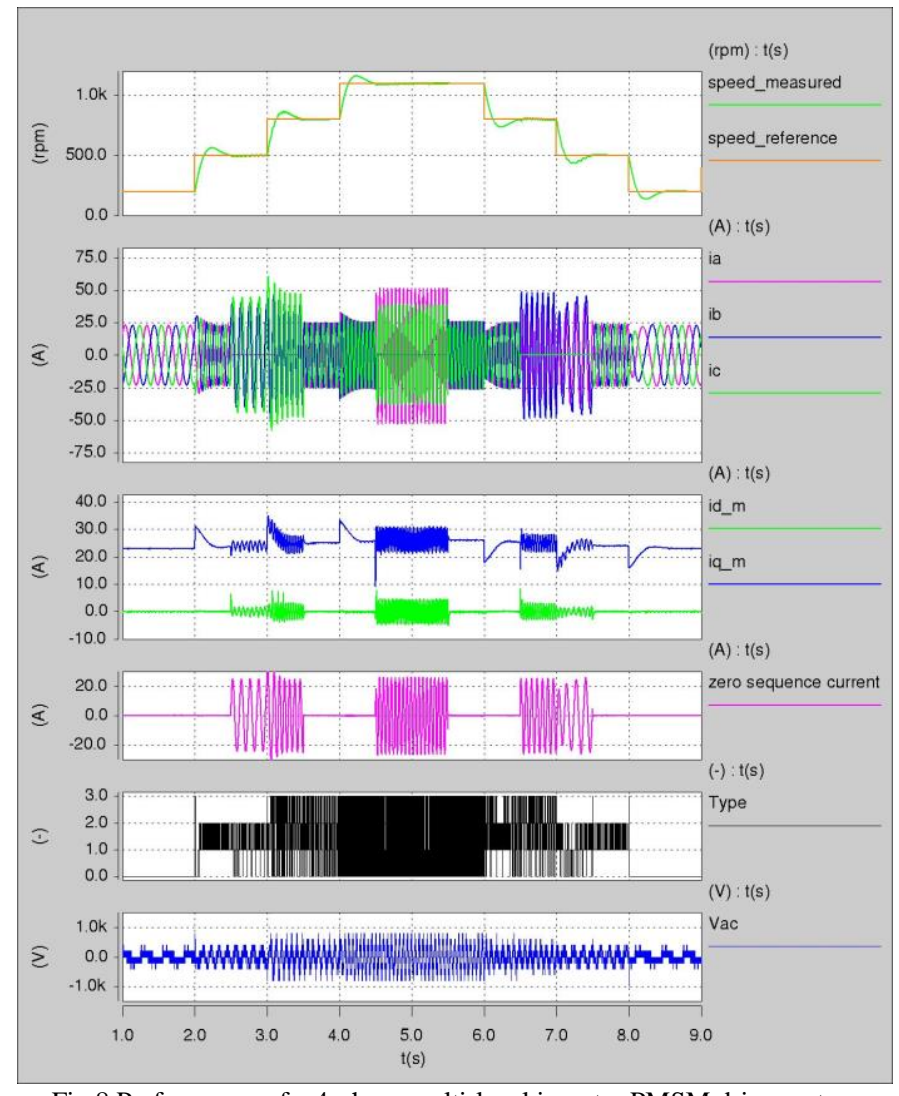

Fig 8 Performance of a 4-phase multi-level inverter PMSM drive system under different operating conditions.

\section{$D$. Tracking the saturation saliency of PMSM under healthy condition}

The stator leakage inductances of the induction motor are modulated by anisotropy either from the rotor slotting or from the saturation of the main flux. The modulation can be expressed by the following equations :-

$l \sigma a=L_{0}+\Delta L \cos \left(n_{a n} \theta_{a n}\right)$

$l \sigma b=L_{0}+\Delta L \cos \left(n_{a n}\left(\theta_{a n}-\frac{2 \pi}{3}\right)\right.$

$l \sigma c=L_{0}+\Delta L \cos \left(n_{a n}\left(\theta_{a n}-\frac{4 \pi}{3}\right)\right.$

Where $L_{0}$ is the average inductance and $\Delta L$ is the variation of leakage inductance due to the rotor anisotropy $\left(n_{a n}=2\right.$ for saturation anisotropy )

This modulation of the stator leakage inductances will be reflected in the transient response of the motor line current to the test vector imposed by the inverter. So by using the fundamental PWM waveform and by measuring the transient current response to the active vectors it is possible to detect the inductance variation and track the rotor position for three-leg multilevel inverter. After obtaing the scalar quantities pa, pb and $\mathrm{pc}$ then the position of the saliency can be constructed as shown in the equation below:-

$$
\overrightarrow{\mathrm{p}}=\mathrm{p}_{\alpha}+j p_{\beta}=\mathrm{p}_{\mathrm{a}}+a p_{\mathrm{b}}+\mathrm{a}^{2} \mathrm{p}_{\mathrm{c}}(5)
$$

Fig 9 shows simulation results for tracking the saturation saliency (2fe) in a SMPM under faulted condition as well as under healthy condition. The motor is driven by a four- leg multi-level inverter. The algorithm that is used in this test track the saliency is proposed in [12] where it is used track the saliency of the SMPM motor driven by a three-leg multilevel inverter under healthy operation. The results shows that under health operating conditions, the algorithm that is used in[12] for three-leg multi-level inverter drive could track the saturation saliency efficiently at different speeds while it couldn't track the saturation saliency under faulted operating conditions i.e in time intervals $(2.5 \mathrm{~s}$ to $3.5 \mathrm{~s}),(4.5 \mathrm{~s}$ to $5.5 \mathrm{~s})$ and $(6.5 \mathrm{~s}$ to $7.5 \mathrm{~s})$. This results can be explained as follows: under healthy operating conditions, the switches in the fourth leg will not be activated and hence the four-leg multi-level inverter will operate as a three-leg multi-level inverter so the algorithm proposed in [12] could track the saliency. In time interval $(2.5 \mathrm{~s}$ to $3.5 \mathrm{~s}$ ) i.e open phase fault in phase a, the measurement of the current response (dia/dt) will become zero as ia $=0$. And so the position estimation algorithm couldn't track the saliency in this time interval. Also between $4.5 \mathrm{~s}$ and $5.5 \mathrm{~s}$ i.e open phase fault in phase $b$ and between 6.5 s to 7.5 s i.e open phase fault in phase $\mathrm{c}$, the measurements of the current responses (dib/dt) and (dic/dt) will become zeros and hence the algorithm couldn't track the saliency in those time intervals as shown in Figure 9.

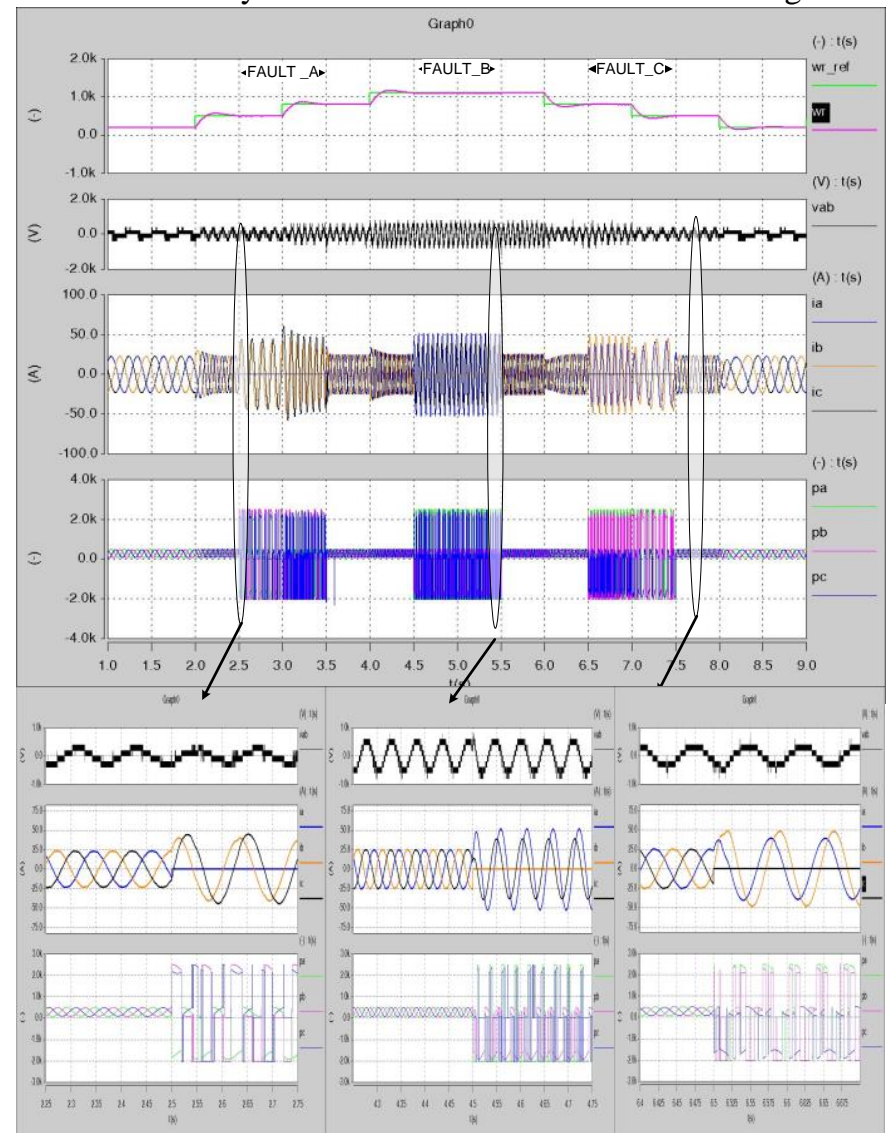

Figure 9. Tracking the saliency saturation in healthy mode and open circuit fault mode as given in [12].

\section{E. Tracking Tracking the Saliency in Multilevel Inverter under unhealthy condition}

As seen in previous section, the algorithm presented in [12] couldn't track the saliency under the case of an open circuit fault. In this section a modified algorithm is introduced to track the saliency in case of an open circuit fault. This algorithm is making use of the switching action of the IGBTs in the fourth 
leg of the multi-level inverter under faulted conditions. It uses the current response of application of fundamental PWM waveform (no modification applied to the PWM waveform). The new algorithm uses only the current response of healthy phases to track the saliency and doesn't use the current response of the open circuit phase as it will be zero. After measuring the current response of the two healthy phases and according to the sector number and the type of the space vector modulation state diagram that the reference voltage exist in, the three position scalars quantities can be deduce and hence the saliency position can be obtained.

Fig 10 shows the Type0 switching sequence of the 4-leg multilevel inverter under phase $\mathrm{c}$ open circuit fault and activating the fourth leg.

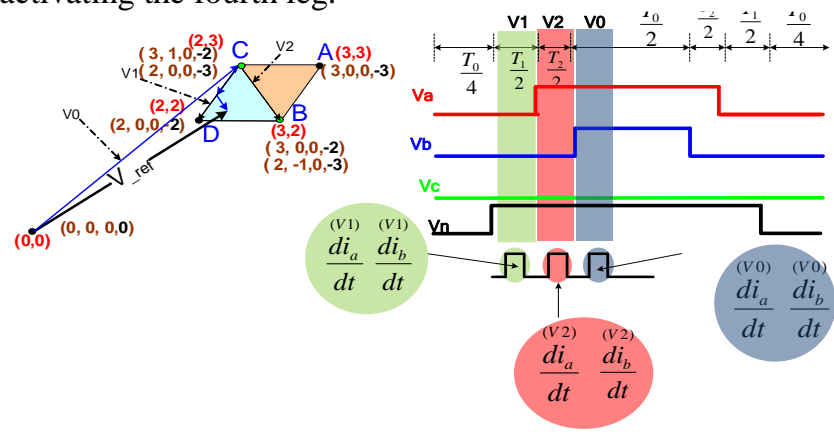

Fig 10 Switching sequence for Type 0 in sector 1 in the multilevel space diagram under phase $\mathrm{c}$ open circuit fault and the fourth leg is activated.

The stator circuit when the vectors V1, V2 and V0 are applied are shown in Fig 11.a, 11.b and 11.c respectively.

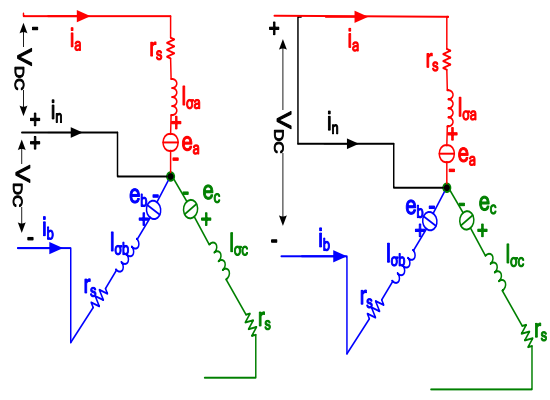

(a)

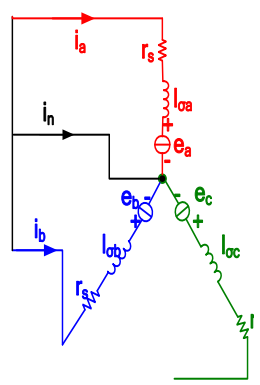

(c)
Fig 11 Stator circuits when: (a) V1 is applied; (b) V2 is applied; (c) V0 is applied.

Using the circuit in Fig 11.a, the following equations hold true:-

$-\mathrm{V}_{\mathrm{DC}}=r_{s} * i_{a}^{(V 1)}+l_{\sigma a} * \frac{d i_{a}^{(V 1)}}{d t}+e_{a}^{(V 1)}(6)$

$-\mathrm{V}_{\mathrm{DC}}=r_{s} * i_{b}{ }^{(V 1)}+l_{\sigma b} * \frac{d i_{b}^{(V 1)}}{d t}+e_{b}^{(V 1)}(7)$

The following equations are obtained using Fig 11.b:-

$0=r_{s} * i_{a}{ }^{(V 2)}+l_{\sigma a} * \frac{d i_{a}^{(V 2)}}{d t}+e_{a}^{(V 2)}(8)$

$-\mathrm{V}_{\mathrm{DC}}=r_{s} * i_{b}^{(V 2)}+l_{\sigma b} * \frac{d i_{b}^{(V 2)}}{d t}+e_{b}^{(V 2)}(9)$

Finally when V0 is applied as shown in Fig 11.c, the

following equations hold true:-

$0=r_{s} * i_{a}^{(V 0)}+l_{\sigma a} * \frac{d i_{a}^{(V 0)}}{d t}+e_{a}^{(V 0)}(10)$

$0=r_{s} * i_{b}^{(V 0)}+l_{\sigma b} * \frac{d i_{b}^{(V 0)}}{d t}+e_{b}^{(V 0)}(11)$
Assuming that the voltage drop across the stator resistances are small and can be neglected and the back emf can be cancelled if the time separation between the vectors is small.

Subtracting equation (8) from equations (6) and equation (11) from equation (9) respectively yields:-

$\mathrm{V}_{\mathrm{DC}}=l_{\sigma a} *\left(\frac{d i_{a}^{(V 2)}}{d t}-\frac{d i_{a}^{(V 1)}}{d t}\right)(12), \mathrm{V}_{\mathrm{DC}}=l_{\sigma b} *\left(\frac{d i_{b}^{(V 2)}}{d t}-\frac{d i_{b}^{(V 0)}}{d t}\right)$

Finally:

$P_{a}=l_{\sigma a} *\left(\frac{d i_{a}^{(V 2)}}{d t}-\frac{d i_{a}^{(V 0)}}{d t}\right)(14), P_{b}=l_{\sigma b} *\left(\frac{d i_{b}^{(V 0)}}{d t}-\frac{d i_{b}^{(V 1)}}{d t}\right)(15)$

Pc cannot be obtained from measuring the current response in phase $\mathrm{c}$ as it is zero in the case of an open circuit phase fault. But it can be deduced from $P_{a}$ and $P_{b}$ according to the following equation:

$P_{c}=-P_{a}-P_{b}(16)$

By doing the same procedures for type 1, type 2 and type 3 in sector 1 , table 1 can be constructed to track the saliency in case of phase $\mathrm{c}$ open circuit fault of four leg-multilevel inverter.

Table 1. Selection of pa, pb, and pc in sector 1 for a star-connected machine driven by 4-leg multilevel inverter in case of phase a open circuit fault.

\begin{tabular}{|c|c|c|c|c|}
\hline \multicolumn{5}{|c|}{ Sector 1} \\
\hline Triangle & Vectors & $\mathrm{Pa}$ & $\mathrm{Pb}$ & $\mathrm{Pc}$ \\
\hline $\begin{array}{l}\text { Type0 } \\
\Delta \mathrm{BCD}\end{array}$ & $\mathrm{V} 1, \mathrm{~V} 2$, Vo & $\left(\frac{d i_{a}}{d t}-\frac{(V 2)}{d t}\right)$ & $\left(\frac{d i_{b}}{d t}-\frac{d i_{b}}{d t}\right)$ & $-\left(P_{a}+P_{b}\right)$ \\
\hline $\begin{array}{r}\text { Type1 } \\
\triangle \text { BCA }\end{array}$ & $\mathrm{V} 1, \mathrm{~V} 2, \mathrm{Vo}$ & $\left(\frac{(V 0)}{d i_{a}} d-\frac{(V 1)}{d t}-\frac{d i_{a}}{d t}\right)$ & $\left(\frac{d i_{b}}{d t}-\frac{d i_{b}}{d t}\right)$ & $-\left(P_{a}+P_{b}\right)$ \\
\hline $\begin{array}{c}\text { Type } \\
2 \\
\Delta \mathrm{BCD}\end{array}$ & $\mathrm{V} 1, \mathrm{~V} 2, \mathrm{Vo}$ & $\left(\frac{(V 0)}{d t}-\frac{(V 1)}{d t}\right)$ & $\left(\frac{d i_{b}}{d t}-\frac{d i_{b}}{d t}\right)$ & $-\left(P_{a}+P_{b}\right)$ \\
\hline $\begin{array}{c}\text { Type } \\
3 \\
\Delta \mathrm{BCA}\end{array}$ & $\mathrm{V} 1, \mathrm{~V} 2, \mathrm{Vo}$ & $\left(\frac{d i_{a}}{d t}-\frac{d i_{a}}{d t}\right)$ & $\left(\frac{d i_{b}}{d t}-\frac{d i_{b}}{d t}\right)$ & $-\left(P_{a}+P_{b}\right)$ \\
\hline
\end{tabular}

The above procedures can be redone for other sectors and for other types of fault i.e phase a open circuit fault and phase $b$ open circuit fault and so an algorithm to track the saliency of the four-leg multi-level drive in case of an open circuit fault can be constructed regardless in which phase is the fault.

Fig 12 shows a simulation results for applying the new algorithm to track the saliency in case of an open circuit fault regardless in which phase is the fault. In the time intervals $(2.5 \mathrm{~s}$ to $3.5 \mathrm{~s}),(4.5 \mathrm{~s}$ to $5.5 \mathrm{~s})$ and $(6.5 \mathrm{~s}$ and $7.5 \mathrm{~s})$, open circuit faults were introduced to the operation of the system. Fig 12 shows that the new algorithm could track the saliency under the conditions of an open circuit fault with the same quality as those obtained under healthy condition.

\section{F. Fully sensorless speed control of 4-leg multilevel inverter under unhealthy condition}

The speed control for a PM machine have been implemented in simulation in the SABER modeling environment. The estimated position signals $\mathrm{P} \alpha \beta$ from the equations selected are used as the input to a mechanical observer [25] to obtain the speed $\omega^{\wedge}$ and a cleaned position $\theta^{\wedge}$. Note that the simulation includes a minimum pulse width of $10 \mathrm{mu} \mathrm{s}$ when $\mathrm{di} / \mathrm{dt}$ measurements are made, similar to the experimental results of [6]. This estimated speed $\omega^{\wedge}$ and position $\theta^{\wedge}$ are used to obtain a fully sensorless speed control as shown in Figure 13. 


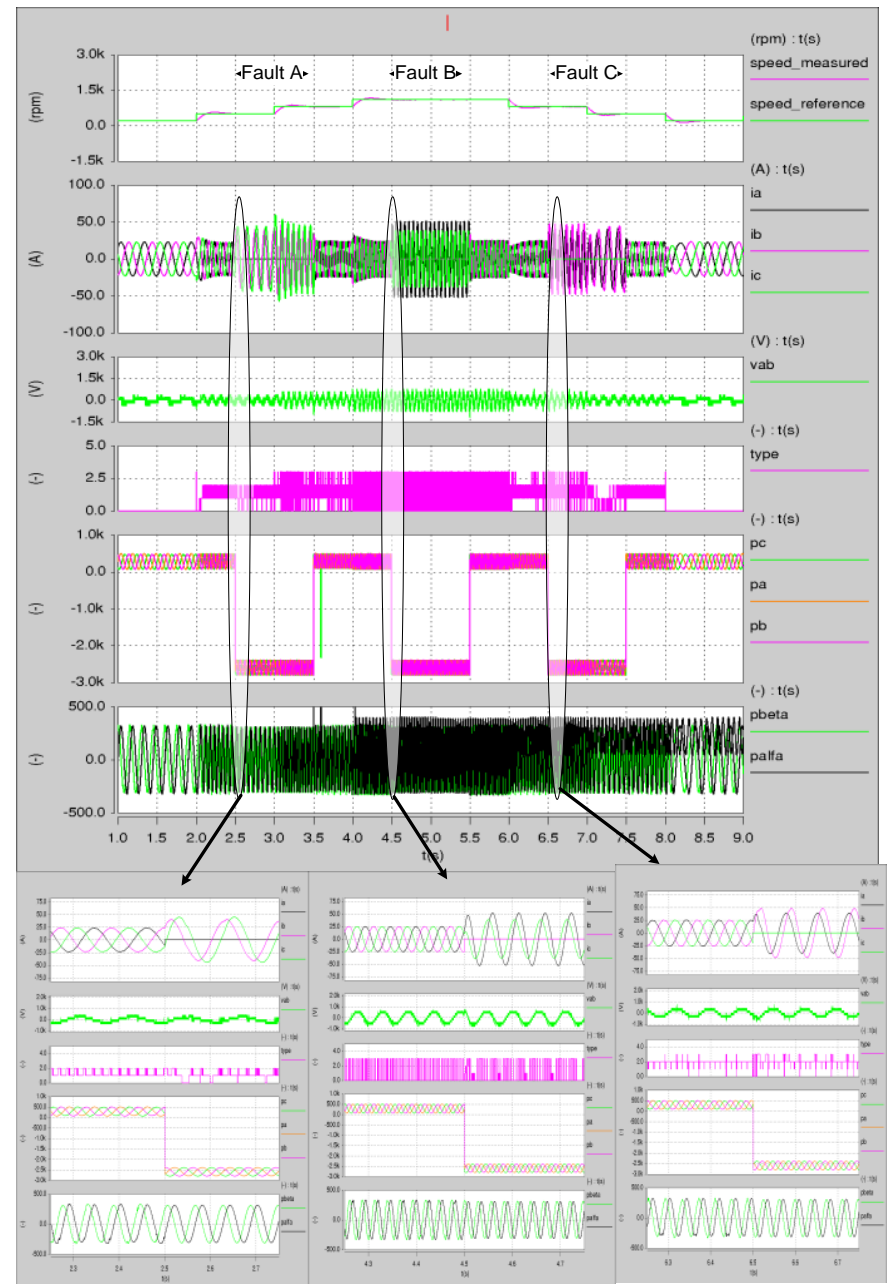

Fig 12 The algorithm to track the saliency in of multilevel inverter using the fundamental PWM algorithm given in [12] for helathy mode and the algorithm presented above for unhealthy condition.

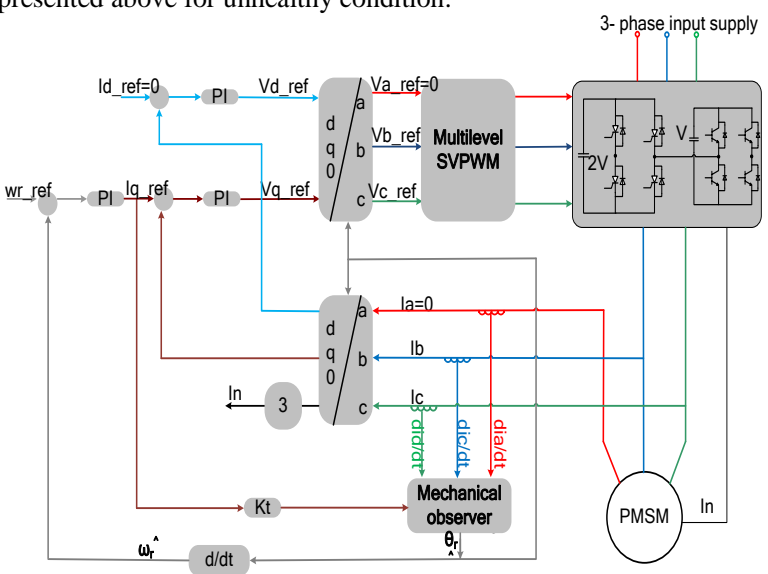

Figure 13. The sensorless vector control structure for the 4-leg multi-level inverter PMSM drive under aa open-circuit fault.

Figure 14 shows the results of a fully sensorless speed control of a PMSM motor driven by a 4-leg multi-level inverter at loaded condition using the algorithm proposed in [12 ] for the healthy case and the method proposed above in the case of an open circuit fault. The motor was working in sensorless healthy mode at speed $=0.5 \mathrm{~Hz}$ then at time $\mathrm{t}=4 \mathrm{~s}$ an open circuit fault in phase ' $a$ ' is introduced to the system. The motor maintained its performance after the fault. At $\mathrm{t}=6 \mathrm{~s}$ a speed step change from $0.5 \mathrm{~Hz}$ to $0 \mathrm{~Hz}$ is applied to the system while the motor was under open circuit fault in phase 'a'. Figure 14 shows that the motor responded to the speed step with a good transient and steady state response. When $\mathrm{t}=8 \mathrm{~s}$, the fault in phase ' $\mathrm{a}$ ' is removed and introduced to phase ' $b$ ', Figure 14 shows the motor was tracking the zero reference speed during this time. At $t=12 s$, the fault is removed from phase ' $b$ ' and introduced to phase ' $c$ '. After that, when $\mathrm{t}=14 \mathrm{~s}$, a speed step change from 0 rpm to $-0.5 \mathrm{~Hz}$ is applied to the system while the motor was working under open circuit fault in phase 'c'. Figure 14 shows that the motor responded to the speed step with good transient and steady state response. Finally, at $t=16 \mathrm{~s}$, all the faults are removed and the motor returns to healthy condition.

Figure 15 shows similar results to those shown in Figure 14 of but at higher speed steps $(16.67 \mathrm{~Hz}$ to 0 to $-16.67 \mathrm{~Hz})$. The motor was working in sensorless healthy mode at speed $=16.667$ $\mathrm{Hz}$ then at time $\mathrm{t}=4 \mathrm{~s}$ an open circuit fault in phase ' $\mathrm{a}$ ' is introduced to the system. The motor maintained its performance after the fault. At $\mathrm{t}=6 \mathrm{~s}$ a speed step change from $16.66 \mathrm{~Hz}$ to 0 $\mathrm{Hz}$ is applied to the system while the motor was under open circuit fault in phase 'a'. Figure 15 shows that the motor responded to the speed step with a good transient and steady state response. When $t=8 \mathrm{~s}$, the fault in phase ' $a$ ' is removed and introduced to phase ' $b$ ', Figure 15 shows the motor was tracking the zero reference speed during this time. At $t=12 \mathrm{~s}$, the fault is removed from phase ' $b$ ' and introduced to phase ' $c$ '. After that, when $t=14 \mathrm{~s}$, a speed step change from $0 \mathrm{rpm}$ to $-16.67 \mathrm{~Hz}$ is applied to the system while the motor was working under open circuit fault in phase 'c'. Figure 15 shows that the motor responded to the speed step with good transient and steady state response. Finally, at $\mathrm{t}=16 \mathrm{~s}$, all the faults are removed and the motor returns to healthy condition.

\section{CONCLUSION}

This paper has outlined a new scheme for tracking the saliency of a motor fed by a 4-leg multi-level inverter in the case of a single phase open circuit fault through measuring the dynamic current response of the motor line currents due to the IGBT switching actions. The proposed method includes software modification to the method proposed in [12] to track the saliency of the motor under healthy conditions to make it applicable in the cases of open circuit phase condition. The new strategy can be used to track the saturation saliency in PM motors $(2 \mathrm{fe})$ and the rotor slotting saliency in IMs (14*fr) similar to the method used in a healthy motor drive and the only difference between the PM and IM will be the tracked harmonic number. The results have shown the effectiveness of the new method in increasing the safety measures in critical systems that need continuous operation. The drawbacks of this method are increasing the total harmonic distortion of the motor's current, specially at a very low speed, due to the minimum pulse width in addition to the need for $3 \mathrm{di} / \mathrm{dt}$ sensors.

\section{References}

[1] Jansen PL, Lorenz RD. Transducerless position and velocity estimation in induction and salient AC machines. IEEE T Ind Appl 1995; 31:240-247.

[2]Jung-IkH, OhtoM, Ji-Hoon J, Seung-Ki S. Design and selection of AC machines for saliency-based sensorless control. In: IEEE2002Industrial Applications Conference; 13-18 October 2002; Pittsburgh, USA. NewYork, NY, USA: IEEE.pp.1155-1162. 
[3] Linke M, Kennel R , Holtz J. Sensorless speed and position control of synchronous machines using alternating carrier injection. In: IEEE 2003 International Electric Machines and Drives Conference; 1-4 June 2003; Wisconsin, USA. New York, NY, USA: IEEE.pp.1211-1217.

[4] Schroedl M. Sensorless control of AC machines at low speed and standstill based on the INFORM method. In:IEEE 1996 Industry Applications Conference; 6 -10 October 1996; San Diego,

[5] HoltzJ, Juliet J. Sensorless acquisition of the rotor position angle of induction motors with arbitrary stator winding. In:IEEE 2004 Industry Applications Conference; 3-7 October 2004;Washington, USA. NewYork, NY, USA: IEEE. pp.1321-1328

[6] Qiang G, Asher GM, Sumner M, Makys P. Position estimation of AC machines at all frequencies using only space vector PWM based excitation.In: IET 2006 International Conference on Power Electronics, Machines and Drives; 4-6 April 2006; Dublin, Ireland. Savoy Place, London, UK: IET.pp. 6170

[7] M.D.Manjrekar, P.K.Steimer, T.A.Lipo," Hybrid Multilevel Power Conversion System: A competitive Solution for High-Power Applications", IEEE transactions on industry applications, volume 36, pp $834-841$, (2000) [8] Sanmin Wei, Bin Wu, Qianghua Wang , “An Improved Space Vector PWM Control Algorithm for Multilevel Inverters", Power Electronics and Motion Control Conference, vol.3,pages:1124-1129, Aug, 2004.

[9] K. Saleh, G.M. Asher, M. Sumner, M. Tomasini, G. Qiang. "Low Speed Sensorless Control of an Induction Motor Fed by Multilevel Converter to Reduce Current Distortion”, EPE 2009 in Barcelona.

[10] Jie Zhang, "Speed sensorless AC drive fed by three-level inverter with fulldimensional spiral vector control for improved low-speed performance," Industry Applications Conference, 1996. Thirty-First IAS Annual Meeting, IAS '96., Conference Record of the 1996 IEEE, San Diego, CA, 1996, pp. 243-249 vol.1.

[11] O. Chandra Sekhar and K. Chandra sekhar, "A novel five-level inverter topology for DTC induction motor drive," 2012 IEEE International Conference on Advanced Communication Control and Computing Technologies (ICACCCT), Ramanathapuram, 2012, pp. 392-396.

[12] k.saleh, M.sumner. "Modelling and Simulation of a Sensorless Control of a True Asymmetric Cascade H-Bridge Multilevel Inverter PMSM Drives. International Journal of Power Electronics and Drive System (IJPEDS) Vol. 7, No. 2, June 2016, pp. 397 415

[13] M. S. Mendes and A. J. Cardoso. "Fault-tolerant operating strategies applied to three-phase induction motor drives", IEEE Transaction on Industrial Electronic., vol. 53, pp. 1807-1817, (2006).

[14] N. Bianchi, S. Bolognani, M. Zigliotto, M. Zordan."Innovative remedial strategies for inverter faults in IPM synchronous motor drives", IEEE Transaction on Engergy Convervsion., vol. 18, pp. 306-314, (2003).

[15] F. Meinguet and J. Gyselinck, "Control strategies and reconfiguration of four-leg inverter PMSM drives in case of single-phase open-circuit faults," 2009 IEEE International Electric Machines and Drives Conference, Miami, FL, 2009, pp. 299-304

[16] SHu, Z., Gui, W., Yang, C. et al. Int. J. "Fault Classification METHOD FOR INVERTER BASED ON HYBRID SUPPORT VECTOR MACHINES AND WAVELET ANALYSIS ," INTERNATIONAL JOURNAL OF CONTROL, Automation AND Systems, August 2011,volume 9, PP. 797-804.

[17] B. A. Welchko, T. A. Lipo, T. M. Jahns and S. E.Schulz. "Fault tolerant three-phase ac motor drive topologies: a comparison of features, cost, and limitation", IEEE Transaction o Power Electronic., vol. 19, pp. 1108-1116, (2004)

[18] S. Khwan-on, L. De Lillo, P. W. Wheeler, and L. Empringham, "Fault tolerant four-leg matrix converter motor drive topologies for aerospace applications," in Proc. IEEE ISIE, 2010, pp. 2166-2171.

[19] Mohammad Ali Paymani, Mohammad Saleh Marhaba and H. Iman-Eini, "Fault-tolerant operation of a medium voltage drive based on the Cascaded $\mathrm{H}$ bridge inverter," 2011 2nd Power Electronics, Drive Systems and Technologies Conference, Tehran, 2011, pp. 551-556.

[20] G. Grandi, P. Sanjeevikumar, Y. Gritli and F. Filippetti, "Experimental investigation of fault-tolerant control strategies for quad-inverter converters," 2012 Electrical Systems for Aircraft, Railway and Ship Propulsion, Bologna, 2012, pp. 1-8.

[21] M. Alavi, D. Wang and M. Luo, "Model-based diagnosis and fault tolerant control for multi-level inverters," IECON 2015 - 41 st Annual Conference of the IEEE Industrial Electronics Society, Yokohama, 2015, pp. 001548-001553.

[22] K. Thantirige, S. K. Panda, A. K. Rathore, S. Mukherjee, M. A. Zagrodnik and A. K. Gupta, "Fault-tolerant cascaded multi-level inverter with improved output quality," 2016 IEEE International Conference on Sustainable Energy Technologies (ICSET), Hanoi, 2016, pp. 332-337.

[23] k.saleh, M.sumner." Modeling and simulation of sensorless control of fourleg inverter PMSM drives in the case of a single-phase open circuit fault". Turkish Journal of Electrical Engineering \& Computer Sciences. Vol 24 Pp:3807-3820 2016.

[24] k.saleh, M.sumner . "Sensorless Control of a Fault Tolerant PMSM Drives in Case of Single-phase Open Circuit Fault". Vol 7.pp:1061-1074. 2016

[25 Lorenz RD, Van Patten KW. High-resolution velocity estimation for alldigital, ac servo drives. IEEE Transaction in Industrial Applications. 1991; 27: 701-705

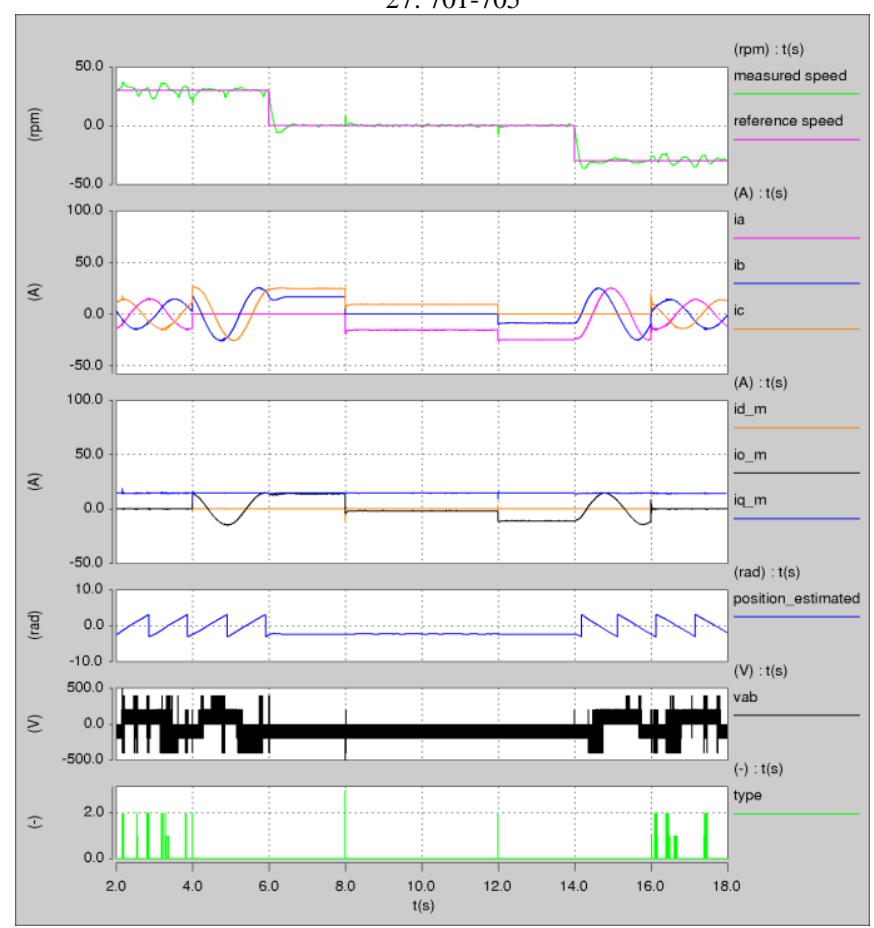

Figure 14. Fully sensorless speed steps between $0.5 \mathrm{~Hz}, 0$ to $-0.5 \mathrm{~Hz}$ under healthy condition and under open circuit fault condition.

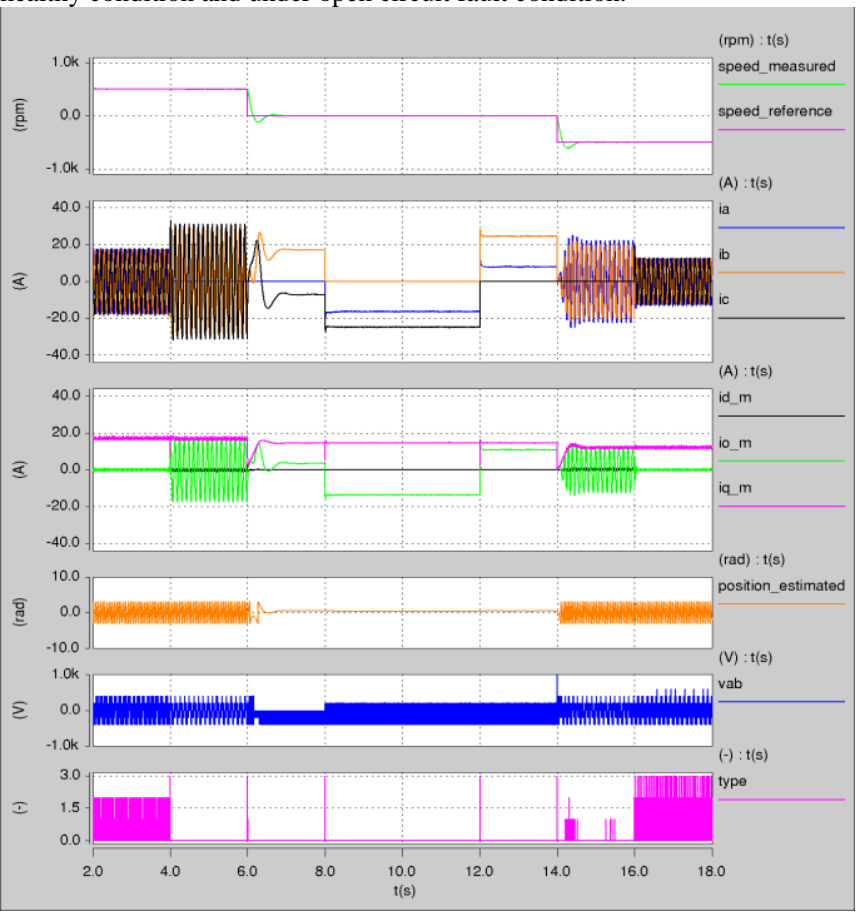

Fig 15. Fully sensorless speed steps between $16.67 \mathrm{~Hz}, 0$ to $-16.67 \mathrm{~Hz}$, under healthy condition and under open circuit fault condition. 